\title{
A Comparative Study of the Heamostatic effect of Topical Tranexamic Acid vs. Adrenaline in Idiopathic Anterior Epistaxis
}

\author{
Essam Ali Abo El-Magd* \\ Assistant professor of Otorhinolaryngology, Aswan Faculty of Medicine, Aswan University, Egypt
}

Submission: August 29, 2017; Published: September 07, 2017

*Corresponding author: Essam Ali Abo El-Magd, Otolaryngology Department, Aswan Faculty of Medicine, Aswan University, Aswan, Egypt, Tel: 00201003406024; Fax: 0020972430767; Email: esamali801@yahoo.com

Abstract

Background: Epistaxis is one of the most prevalent emergencies in ENT practice. Sixty percent of people experience it at least once in their life. Although the majority of cases are easily controlled, there are different modalities of treatment for epistaxis either medically or surgically. The condition can occur at any age but is mainly seen in adults.

Objective: To compare the decongestive effect of topical tranexamic acid and adrenaline in controlling active idiopathic anterior epistaxis in adults before cauterization.

Patients and Methods: A prospective study carried out in otolaryngology departments of Aswan University Hospital, Egypt in the period between June 2015 and December 2015 after the license from Aswan Faculty of Medicine ethics committee. 160 adult patients presented with anterior epistaxis were classified into two groups based on the method used for management of epistaxis. In the first group, 80 patients used adrenaline $(1: 10,000)$ soaked cotton packs for control of active bleeding. The second group, 80 patients used a piece of cotton pled get soaked in inject able form of tranexamic acid ( $500 \mathrm{mg}$ in $5 \mathrm{ml}$ ).

Results: In the first group, 72 patients out of $80(90 \%)$ had successful control of bleeding following use of $(1: 10,000)$ adrenaline-soaked cotton packs for 10 minutes prior to cauterization. In the second group, 66 patients out of 80 (82.5\%) had successful control of bleeding following use of tranexamic acid-soaked cotton packs for 10 minutes prior to cauterization.

Conclusion: Topical application of injectable form of tranexamic acid is a successful and effective treatment for patients with anterior idiopathic epistaxis followed by silver nitrate cauterization and risks of anterior nasal packing can be avoided. Although the higher success rate in the first group managed with local adrenaline, it is not suitable in patients with hypertension, coronary artery diseases, cardiovascular diseases, myocarditis and in patients treated with beta blockers. Local tranexamic acid can safely replace adrenaline in these cases.

Keywords: Anterior idiopathic epistaxis; Tranexamic acid; Adrenaline

\section{Introduction}

Epistaxis is one of the commonest otolaryngological emergencies, occurring in $60 \%$ of adults over their lifetimes, but treatment is required in only $10 \%$ of cases [1] Yuji 2014. Many risk factors for adult epistaxis have been reported, but most of them are generally controversial. In terms of age, epistaxis is believed to occur more frequently in the age range of 45-65 years [2] yuji. In terms of sex ratio, it is more common among men up to the age of 49 years, but after that, it occurs at the same frequency among men and women, suggesting that estrogen may be involved $[3,4]$. The use of antithrombotic agents is believed to be A high-risk factor for epistaxis, but whether its discontinuation is necessary is controversial. Although one report stated that discontinuing antithrombotic agents was unnecessary in people with epistaxis
[5]. The relationship between hypertension and epistaxis is also unconfirmed. Although some studies have found a correlations between hypertension and epistaxis [6-8], others have ruled it out $[9,10]$. Another report identified longstanding hypertension as increasing the risk of epistaxis [11].

One expert claims that although hypertension does not cause epistaxis, it results in protracted bleeding [12]. Most of epistaxis issue is due to rupture of blood vessel on the nasal septum. The key to effective management of these patients lies in identification of the bleeding point and subsequent cauterization Owais [13]. Epistaxis has traditionally been divided into anterior and posterior, based on the site of bleeding. Anterior epistaxis is bleeding from source anterior to the plane of piriform aperture, 
while posterior epistaxis being from vessel situated posterior to the piriform aperture [14]. For anterior epistaxis straightforward identification of bleeding point is essential and direct treatments are practically superior. The success of direct treatment, which is silver nitrate cauterization depends on how dry the anterior bleeding focus was prior to cauterization $[14,15]$. Our study was under taken to study the methods of controlling idiopathic anterior epistaxis by achieving a dry focus of bleeding site for successful cauterization. We compare the role of local tranexamic vs local adrenaline as haemostatic agents in achieving successful control of arterial spurts before cauterization.

\section{Methods}

A prospective study carried out in otolaryngological department, Aswan faculty of medicine, Aswan University, Egypt in the period between June 2015 and December 2015 after the license from Aswan Faculty of Medicine ethics committee. 160 patients with anterior epistaxis were adults between 40 and 70 years. We excluded from our study patients with history of trauma, recent nasal surgery, any bleeding diathesis or patients with earlier intervention on bleeding site at primary health center. All the patients included in the study presented with spontaneous onset of epistaxis and bleeding arterial spurt were clearly identified on anterior rhinoscopy. All the patients were diagnosed as anterior epistaxis with simple nasal examination method using Killian's anterior rhinoscopy. After cleaning, the bleeding nasal cavity with suction apparatus, $10 \%$ xylocain spray was used to anaesthetize the nasal cavity before any further intervention. The 160 patients were divided into two groups randomly and two different treatment modalities were used.

a. Group A: 80 patients presented with anterior epistaxis were included in this group. The bleeding nasal cavity was packed with cotton packs soaked in 1:10,000 adrenaline solutions and kept for 10 minutes. After that cotton packs were removed and nasal cavity was examined again. Patients in whom bleeding was sufficiently controlled due to vasoconstrictor effect of adrenaline were subjected to silver nitrate cauterization. Patients were observed for 1 hour after cauterization and were followed up after 4 days. Patients who were seen bleeding after removal of cotton packs were considered as failure.

b. Group B: 80 patients presented with anterior epistaxis were included in this group. The bleeding nasal cavity was packed with cotton packs soaked in injectable solution of tranexamic acid (500 $\mathrm{ml}$ in $5 \mathrm{ml})$ and kept for 10 minutes. After that cotton packs was removed and nasal cavity was examined again. Patients in whom bleeding was controlled due to haemostatic effect of local tranexamic acid were subjected to silver nitrate cauterization. Patients who were seen bleeding after removal of cotton packs were considered as failure.

\section{Results}

In group A, 72 out of 80 (90\%) patients were found successfully treated and bleeding stopped after 10 minutes application of adrenaline pack. In group B, 66 out of 90 (82\%) patients were found successfully treated and bleeding stopped after removal of tranexamic acid pack within 10 minutes. Failure group patients, i.e. 8 out of 80 in the first group (10\%), 14 out of 80 patients (18\%), were managed with conventional nasal packing for 48 hours. Analysis of statistical data in the two groups shows that adrenaline and local tranexamic used for temporary hemostasis prior to silver nitrate cauterization in anterior epistaxis has not shown much difference. Use of adrenaline has better effect but due to risk associated with it, local tranexamic acid can be safely used in all subjects (Table 1).

Table 1: comparison between group A and group $B$.

\begin{tabular}{|c|c|c|c|}
\hline Groups & $\begin{array}{c}\text { Number of } \\
\text { cases }\end{array}$ & $\begin{array}{c}\text { Successful } \\
\text { cases }\end{array}$ & Percentage \\
\hline Group(A) & 80 & 72 & $90 \%$ \\
\hline Group(B) & 80 & 66 & $82 \%$ \\
\hline
\end{tabular}

p. value : non significant

\section{Discussion}

Epistaxis forms a major's problem of our ENT department in upper Egypt where this study was conducted. It is common and affects all age groups with higher frequency in elderly males [16]. According to the site of bleeding epistaxis has been classified as anterior and posterior epistaxis. In our study group only patients that were diagnosed as idiopathic anterior epistaxis were considered. Most of the patients were elderly in age range 40 to 70 years. The aim of the study was to determine the definitive method of controlling idiopathic anterior epistaxis in adult patients. The study showed that most of the patients can be managed by the use of a local haemostatic agent followed by silver nitrate cauterization in first sitting. This reduces the hazards of anterior nasal packing. Our results are in line with Zahed et al. [17] who reported that local application of injectable form of tranexamic acid resulted in stoppage of bleeding in $71 \%$ of patients within 10 minutes of treatment. Owais et al. [13] recorded a success rate of $90 \%$ with the use of local adrenaline for 10 minutes. The comparative effect of local tranexamic acid and adrenaline for heamostasis to control active bleeding prior to cauterization was studied.

The study result analysis revealed that success rates with these two methods of intervention did not very much. But the use of adrenaline was not suitable in high risk patients with hypertension, cerebrovascular diseases, other vascular diseases and arrhythmogenic drugs like anticonvulsants, etc. It is contraindicated in patients on non selective beta blockers, tricyclic antidepressant. From this study, we concluded that the difference in the success rates of local tranexamic acid and adrenaline does not vary much statistically and thus local tranexamic acid can safely replace adrenaline in cases where 
adrenaline is contraindicated or in cases where there is a caution in its use.

\section{Conclusion}

Local tranexamic acid can safely replace adrenaline to control bleeding in cases of idiopathic anterior epistaxis prior to silver nitrate cauterizfation.

\section{References}

1. Yuji A, Jiro L, Satoshi A, Komori M, Tsuyumu M, et al. (2014) Risk factors for recurrent epistaxis: importance of initial treatment. Auris Nasus Larynx 41(1): 41-45.

2. Watkinson JC, Mackay IS, Bull TR (1997) Scott Brown's otolaryngology: 5-7.

3. Tomkinson A, Robin DG, Flanagan P, Quine SM (1997) Pattern of hospital attendance with epistaxis. Rhinology 35(3): 129-131.

4. Daniell HW (1995) Estrogen prevention in recurrent epistaxis. Arch Otolaryngology Head Neck Surg 121: 354.

5. Nitu IC, Perry DJ, Lee CA (1998) Clinical experience with the use of clotting factor concentrates in oral anticoagulation reversal. Clin Lab Heamatol 20: 363-367.

6. Kotecha B, Fowler S, Harkness P, Walmsl (1996) Management of epistaxis: a natutinal survey. Ann R Coll Surg Engl 78: 444-446.

7. Okafor BC (1984) Epistaxis: a clinical study of 540 cases. Ear Nose Throat J 63: 153-159.
8. Elden L, Montanera W, Terbrugge K (1994) Angiographic embolization for the treatment of epistaxis: a review of 108 cases. Otolaryngol Head Neck Surg 111: 44-50.

9. Petruson B, Rudin R, Sardsudd K (1977) Is high blood pressure an eatiological factor in epistaxis. J Otolaryngol Relat Spec 39: 155-160.

10. Lubianca-Neto JF, Bredemeier M, Arruda CA (1998) A study of the association between epistaxis and the severity of hypertention. Amer J Rhinol 12: 269-272.

11. Lubianca-Neto JF, Fuchs FD. Facco SR (1999) Is epistaxis evidence of end organ damage in patients with hypertention. Laryngscope 109: 1111-1115.

12. Viehweg TL, Robenson JB, Hudson JW (2006) Episaxis: diagnosis and treatment. Oral Maxillofac Surg 64: 511-518.

13. Owais M, Aamir Y (2011) Control of anterior epistaxis: A comparative analysis of the decongestive effect of xylomtazoline and adrenaline. Clinical Rhinology 4(3): 130-135.

14. McGarry Gw (2008) Epistaxis Scott-Brown's otolaryngology, head and neck surgery ( $7^{\text {th }}$ edn). London Hodder Arnold 2: 1596-1608.

15. Pearson BW (1983) Epistaxis: Some observations on conservative management. The journal of Laryngology and Otology 8: 115-119.

16. Supriya M, Shakeel M (2010) Epistaxis: Prospective evaluation of bleeding site and its impact on patient outcome. The Journal of Laryngology and Otology 124: 744-749.

17. Zahed R, Moharamzadeh P, Saeedi M (2013) A new and rabid method for epistaxis treatment using injectable form of tranexamic acid topically. Am J Emerg Med 31(9): 1389-1392.

\section{Your next submission with Juniper Publishers will reach you the below assets}

- Quality Editorial service

- Swift Peer Review

- Reprints availability

- E-prints Service

- Manuscript Podcast for convenient understanding

- Global attainment for your research

- Manuscript accessibility in different formats

( Pdf, E-pub, Full Text, Audio)

- Unceasing customer service

Track the below URL for one-step submission https://juniperpublishers.com/online-submission.php 